\title{
A percepção de professores de Educação Física sobre uma escrita curricular
}

\section{culturalmente orientada}

\author{
The perception of Physical Education teachers about culturally oriented curricullum writing \\ Percepción de los profesores de Educación Física sobre la redacción del currículo con orientación \\ cultural
}

Recebido: 15/07/2021 | Revisado: 21/07/2021 | Aceito: 23/07/2021 | Publicado: 31/07/2021

\author{
Anna Carolina Carvalho de Souza \\ ORCID: https://orcid.org/0000-0002-7875-6575 \\ Universidade Federal do Rio de Janeiro, Brasil \\ E-mail: uerjanna @gmail.com \\ Silvio de Cassio Costa Telles \\ ORCID: https://orcid.org/0000-0003-2652-6118 \\ Universidade Federal do Rio de Janeiro, Brasil \\ E-mail: silviotelles@terra.com.br
}

\begin{abstract}
Resumo
O currículo cultural da Educação Física questiona a hegemonia das manifestações corporais e os significados dos grupos privilegiados. Baseados na perspectiva da diferença como a própria riqueza da sociedade e na constituição de uma docência atenta à diversidade, articula com o Projeto Pedagógico da escola, valorizando o patrimônio cultural da comunidade como estratégias para eleição dos temas de ensino. Diante disso, o presente estudo buscará analisar a percepção dos professores de Educação Física sobre as orientações pedagógicas vigentes para a disciplina contidas no Projeto Político Pedagógico Institucional (2017-2020) do Colégio Pedro II, que possui uma escrita culturalmente orientada. Como ferramenta metodológica aplicamos um questionário com perguntas abertas e fechadas a 33 docentes, com posterior análise de conteúdo com base em Bardim (2011). Ao analisar as respostas, emergiram 4 categorias: Formação cidadã; Valorização da diversidade e diferença; Valorizar cultura minoritária/ problematização das relações de poder; Interesse do estudante e valorização da própria cultura. Concluímos que há forte influência do currículo cultural nas orientações das ações pedagógicas do grupo de professores investigado, e que há um entendimento sobre o que venha a ser, ainda que momentaneamente, o currículo cultural por parte desse grupo e que as modificações curriculares observadas apontam para o abandono da perspectiva desenvolvimentista nessa instituição.
\end{abstract}

Palavras-chave: Currículo cultural; Multiculturalismo; Educação física; Ensino.

\begin{abstract}
Physical Education's cultural curriculum questions the hegemony of physical manifestations and the significance of the privileged groups. Based on the perspective of difference as society's wealth and on the construction of a teaching profession that is attentive towards diversity, it joins forces with the school's Pedagogical Project, strengthening the community's cultural heritage as a base for choosing teaching themes. With this in mind, the present study seeks to analyze the perception of Physical Education teachers regarding the current pedagogical guidelines for the subject that are contained in the Institutional Political Pedagogical Project (2017-2020) for Colégio Pedro II, which is written in a culturally oriented manner. As a methodological tool, we used a questionnaire with open and closed questions to interview 33 teachers and then applied content analysis based on Bardin (2011). While analyzing the answers, four categories emerged: Citizen education; Valuing diversity and difference; Valuing minority cultures / problematizing relationships of power; Student interest and valuing one's own culture. We concluded that the cultural curriculum strongly influences the guidelines for the pedagogical actions conducted by the group of teachers in question and that there is an understanding among the group, momentary though it may be, regarding what the cultural curriculum seems to be. The curricular modifications that have been observed seem to demonstrate an abandonment of the developmental perspective in this institution.
\end{abstract}

Keywords: Cultural curriculum; Multiculturalism; Physical education; Teaching.

\section{Resumen}

El currículo cultural de Educación Física cuestiona la hegemonía de las manifestaciones corporales y los significados de los grupos privilegiados. Partiendo de la perspectiva de la diferencia como riqueza misma de la sociedad y la constitución de una enseñanza atenta a la diversidad, se articula con el Proyecto Pedagógico de la escuela, valorando el patrimonio cultural de la comunidad como estrategias para la elección de temas didácticos. Por tanto, este estudio 
buscará analizar la percepción de los docentes de Educación Física sobre los lineamientos pedagógicos vigentes para la disciplina contenidos en el Proyecto Político Pedagógico Institucional (2017-2020) del Colégio Pedro II, que tiene una redacción de orientación cultural. Como herramienta metodológica, se aplicó un cuestionario con preguntas abiertas y cerradas a 33 docentes, con posterior análisis de contenido basado en Bardim (2011). Al analizar las respuestas surgieron 4 categorías: Formación ciudadana; Valorar la diversidad y la diferencia; Valorar la cultura minoritaria / problematizar las relaciones de poder; Interés y aprecio de los estudiantes por su propia cultura. Concluimos que existe una fuerte influencia del currículo cultural sobre los lineamientos de las acciones pedagógicas del grupo de docentes investigados, y que existe un entendimiento de cuál será el currículo cultural, aunque sea momentáneamente, por parte de este grupo y que el Los cambios curriculares observados apuntan al abandono de la perspectiva de desarrollo en esta institución.

Palabras clave: Currículum cultural; Multiculturalismo; Educación física; Enseñanza.

\section{Introdução}

A construção curricular é resultado de conflitos, de opiniões políticas, fatores culturais e econômicos, é um campo de contestação, representado por ideologia e permeado por relações de poder (Silva, 2015). Na sua composição muitas "vozes" podem ser silenciadas ou autorizadas para pronunciar uma concepção legitimadora (Ferraz \& Correia, 2012).

Na prática, esse conflito e luta por representação curricular, especificamente da Educação Física, foi explicitado por Salgado et.al., (2016) ao demonstrar a tentativa histórica de equalizar a carga horária destinada a disciplina na escola, que encontrava-se em situação de desprivilégio em comparação com outras disciplinas, como português e matemática na instituição que analisaram, demonstrando relações de poder existentes na hierarquia de disciplinas e na sociedade.

Nesse sentido, fica mais evidente a ideia de que "[...] o currículo enfrenta resistência, transgressões e ressignificações. Enfim, o currículo é vivo, dinâmico e resultado do que fazemos dele." (Neira, 2011, p.13). Em sua elaboração, por exemplo, as culturas socialmente marginalizadas podem ser selecionadas, debatidas e contextualizadas ou apenas silenciadas.

Numa análise à história das teorizações curriculares, Lopes e Macedo (2011) indicaram que uma boa teoria curricular deveria se preocupar com as relações de poder subjacentes a cada escolha, e ressaltam que um currículo pós-estrutural é um currículo aberto à diferença. Nesse sentido, Williams (2013) esclarece que o pós-estruturalismo se propõe a desconstruir e transformar determinada estrutura, acreditando que a desconstrução resultará, necessariamente, em uma transformação.

As aproximações entre currículo cultural e o pós-estruturalismo foram enunciadas por Neira e Santos (2019) quando os autores esclareceram que esse currículo [...] busca inspirações nas teorias pós-criticas, (estudos culturais, multiculturalismo crítico, pós-estruturalismo, pós-colonialismo e pós-moderninsmo, entre outras) [...] (p.52). Essa informação nos ajuda a refletir por quais caminhos teóricos o currículo cultural se direciona.

Assim sendo, o pós-estruturalismo é político e visa alterar nossas visões de mundo, como exemplo: as nossas relações com nossos corpos no que se refere a sexualidade, gênero e relações com o ambiente e com o inconsciente, além disso, é constantemente revivido pela abertura ao inédito e diferente (Williams, 2013).

O espaço escolar nem sempre foi um local propício à diferença, à estranheza, ao que não é ortopédico, disciplinado e eficiente, pois tudo aquilo que fugia ao modelo de ordem proposto, (em geral, produtivo, "normal", disciplinado e uniformes) era repugnado (Gomes, Almeida \& Bracht, 2010). Mas sim, um espaço homogeneizador, permeado por questões propensas à reprodução de desigualdades e conhecimentos baseados em princípios e interesses burgueses, envolvendo os educandos em práticas individualizadas, fragmentadas e reafirmadoras de uma sociedade injusta (Venancio \& Darido, 2012). Ou seja, o modelo escolar que teoricamente deveria primar pela heterogeneidade, acaba, por vezes, produzindo homogeneidade pois a educação é encarada como um território em que a ideologia dominante impõe a sua lógica (Neira, 2018a).

Além disso, por vezes, a construção curricular perpassa por um processo alheio aos domínios das instituições escolares, sendo pensada em instâncias acadêmicas concebidas de um "pressuposto saber" que desconsidera o saber produzido pelos protagonistas diretos do conhecimento escolar, os estudantes (Ferraz \& Correia, 2012). Como quando são elaborados 
documentos educacionais norteadores por agentes que não tem conhecimento sobre o cotidiano escolar. Essa construção acaba contribuindo para o desinteresse estudantil, que não ocupam seus lugares de fala e não possuem representatividade nessa escrita, acabam atuando como meros espectadores.

A elaboração do currículo nem sempre articula os interesses dos agentes educativos. Há ainda uma construção verticalizada, com elaboração de projetos pedagógicos desvinculados das realidades cotidianas. A construção do Projeto Político Pedagógico (PPP) é uma forma de contrapor-se à fragmentação do trabalho pedagógico, permitindo uma construção coletiva de um instrumento orientador capaz de auxiliar no enfrentamento de tensões e desafios impostos pelo processo pedagógico (Venancio \& Darido, 2012).

O currículo apresenta um projeto político ou nele se expressam diferentes projetos políticos, que nem sempre convergem ou são bem esclarecidos, sendo, no entanto, o resultado de um acordo mínimo. O que leva Bracht (2019) a questionar se essa construção se dá por meio de uma imposição ou de um acordo, corroborando a sua ideia de que é inegável o distanciamento existente entre o currículo prescrito e o vivido. Além disso, Santos Júnior e Neira (2020) destacam que o currículo traz consigo princípios e valores consequentes da seleção de conhecimentos, ressaltam ainda a construção textual impermeável, que ocorre quando se constrói um currículo centralizado e sem diálogo.

Considerando a relevância da implementação de um PPP articulado com a comunidade escolar, democraticamente construído, o currículo de Educação Física do Colégio Pedro II, que é parte teórica do Projeto Político Pedagógico Institucional (PPPI), contou com a participação de um grupo de vinte e um professores do Departamento de Educação Física (DEF) em seu processo de elaboração e buscou estabelecer diálogos com as teorias curriculares e construir propostas identificadas com as identidades docentes e discentes da comunidade escolar (Colégio Pedro II, 2018).

Salles (2019) em sua tese de doutorado realizou um estudo de caso de natureza histórica, objetivando analisar, com base em pressupostos multiculturais, o currículo da Educação Física do Colégio Pedro II e sua construção, buscando entender, a partir dos discursos dos professores da disciplina, quais os desafios enfrentados ao lidar com a diversidade cultural no contexto do colégio. Esses estudos contribuíram para a construção do atual currículo da disciplina ao longo desse processo de formação continuada.

O currículo de Educação Física do Colégio Pedro II possui como fundamentação teórica, um abordagem que se aproxima do que preconiza o currículo cultural, isso torna-se notório quando o documento revela a importância da valorização do patrimônio cultural dos estudantes, ao tentar atender as demandas e necessidades de uma sociedade multicultural que busca assegurar as diferenças em princípios plurais. Além disso, expõe inúmeras preocupações, orientações e informações que confluem das mesmas ideias do currículo cultural, como quando expõe a necessidade de se pensar em um currículo que evite o daltonismo cultural, que reconheça nossas identidades culturais, promova a ancoragem social dos conteúdos e reconhece a importância do processo de descolonização e da justiça curricular (Colégio Pedro II, 2018).

Segundo Moreira e Candau (2003), quando não se enxerga as diferenças culturais presentes entre os grupos pode surgir o "daltonismo cultural". A atuação docente deve validar a riqueza existente nas diversas histórias e culturas de um mesmo grupo, isso "[...] requer uma postura que supere o "daltonismo cultural" usualmente presente nas escolas, responsável pela desconsideração do "arco-íris de culturas" com que se precisa trabalhar [...]" (Moreira \& Candau, 2003, p.6).

Evitam o daltonismo cultural ao privilegiar temas considerando pertencentes a grupos marginalizados, isto é, representações elaboradas pelos setores desfavorecidos, mas, além disso, ao reconhecerem as singularidades presentes em aula, incluindo-as. As modificações solicitadas pelo docente, ocorrem com intuito de considerar o encontro dos conhecimentos apresentados pelos alunos, professores, convidados... Nesse momento, os estudantes podem ocupar diferentes funções em uma mesma atividade, e terem reconhecidos seus saberes previamente obtidos. Não sofrem interdições, não há correção objetivando o movimento correto, e nem há cobrança sobre o desempenho esperado (Neira, 2020). 
A ancoragem social dos conhecimentos propõe profundidade no tratamento dos temas e engajamento docente, evitando uma abordagem superficial das questões sócio-históricas e políticas, alusivas às práticas corporais. A concepção de currículo descolonizado vincula-se a princípios de valorização e reconhecimento da diversidade indentitária social, objetivando tornar o local propício para que as narrativas da própria cultura se efetivem, relatando conhecimentos, práticas, marcas históricas de luta de grupos dominados e da cultura popular.

Já a ideia de justiça curricular refere-se a seleção justa e equilibrada dos temas de ensino, tanto aqueles trazidos pelos estudante, quanto os originários de outras fontes, valorizando o patrimônio corporal historicamente excluído e atentando-se ao modo como certos conhecimentos tornam-se privilegiados enquanto outros silenciados (Neira, 2011). Sendo assim, é no princípio da justiça curricular "[...] que o professor se apoia para incluir práticas corporais pertencentes a outros grupos sociais, às vezes, pouco representados na escola [...]" (Neves \& Neira, 2019, p.110).

Neira (2011) ainda afirma que intensos processos de hibridização ${ }^{1}$ cultural permeiam a sociedade, pressupondo a não existência de uma cultura pura e nem tampouco melhor. Simultaneamente, o autor expõe que os Estudos Culturais ${ }^{2}$ e o Multiculturalismo crítico objetivam analisar e compreender a formação de identidades culturais híbridas. Nesse sentido, o professor deve reconhecer a história marcada nos corpos de seus estudantes e considerar a diversidade em aula (Daolio, 2010, Lopes \& Macedo, 2011).

O Multiculturalismo crítico analisa entre outros itens, as representações sociais, sejam elas: étnica, de classe, de gênero e religiosa, resultado de lutas sociais amplas (McLaren, 2003). Sendo assim, pensar o currículo cultural pode potencializar vozes e culturas silenciadas e contribuir para valorização das diferenças, combatendo discursos preconceituosos em vista de transformação da escola em um espaço de problematização e produção cultural, em prol de justiça social e curricular, com ênfase no reconhecimento das diferenças e na busca por uma educação escolar efetivamente igualitária e democrática (Moreira \& Candau, 2003; Miskolci \& Júnior, 2014).

Desse modo, temos como objetivo geral: Analisar a percepção dos professores de Educação Física sobre as orientações pedagógicas vigentes para a disciplina contidas no PPPI (2017-2020) do Colégio Pedro II, embasado teoricamente no currículo cultural. Como objetivos específicos: i) problematizar o que os docentes consideram ser ações influenciadas pelo currículo cultural; ii) analisar as modificações curriculares percebidas; iii) identificar o nível de aceitação do currículo cultural como estratégia de ensino desse corpo docente.

\section{Metodologia}

Esse estudo se caracteriza como estudo qualitativo exploratório, que tem como função aumentar a experiência do pesquisador sobre determinado problema, permitindo manejo da temática com maior segurança, pode ser também que o investigador, baseado em uma teoria, busque elementos necessários que lhe permitam, em contato com determinada população, alcançar os resultados esperados, respeitando as características éticas de um trabalho cientifico. Ou seja, as pesquisas qualitativas, não tem caráter especulativo, podem ser usadas, por exemplo, para investigar o processo pedagógico (Triviños, 19987).

\footnotetext{
${ }^{1}$ Hibridismo: combinação de grupos e identidades que resultam em outras, no entanto, renovados (Silva, 2015).

${ }^{2}$ Os Estudos Culturais se propõem a avaliar as práticas culturais e as relações de poder (Nelson, Treichler \& Grossberg, 2013), além disso, objetivam equidade educacional ao relacionar a cultura contemporânea com a sociedade, ampliando as discussões sobre identidade, diferença e processos de subjetivação, rompendo hierarquização e dicotomização (global/local e científico/senso comum), buscando se distanciar do modelo neoliberal de formação cidadã, que incentiva o consumo, e se aproximar de posturas reivindicatórias; criticando a especialização, o etnocentrismo e naturalização do currículo fundamentado pelo discurso tecnicista e da cultura universal (Neira, 2016a; Neira, 2018a).
} 
Este estudo constitui um subprojeto da pesquisa intitulada "A ressignificação curricular na Educação Física: uma perspectiva multicultural”3, e envolveu a interpretação de respostas a um questionário, que visava analisar a percepção docente frente a parte escrita curricular da Educação Física do PPPI do Colégio Pedro II, que está embasado teoricamente no currículo cultural, sendo esta uma das etapas do estudo.

Foi aplicado um questionário composto por 14 perguntas: 6 que buscavam dados pessoais, 6 fechadas e 2 abertas, das questões abertas, uma delas visava analisar a percepção docente frente as mudanças curriculares ocorrida na instituição e a outra objetivava averiguar a visão deles sobre ações culturalmente orientadas.

As 6 primeiras perguntas buscavam dados pessoais, acadêmicos e profissionais, solicitando que obrigatoriamente fossem preenchidas as seguintes informações: endereço eletrônico; campus em que atua; instituição que cursou a graduação; ano de conclusão de curso; ano de admissão no Colégio Pedro II e, opcionalmente, respondessem qual o maior grau de titulação acadêmica.

Posteriormente as perguntas incidiram sob a tentativa principal de identificar se os professores observam diferença entre a proposta pedagógica de 2011 e o novo PPPI do Colégio Pedro II, analisar se eles conhecem o currículo cultural, se consideram sua atuação influenciada pelos princípios ético-políticos que subsidiam tal currículo, o que eles consideram ser uma prática pedagógica culturalmente orientada e se eles analisam as estratégias didático-pedagógicas, por eles empregadas, aproximadas de tais princípios.

Para isso, realizamos as questões adequando ao Formulário Google, ferramenta gratuita disponível na internet, recurso que permite acesso e preenchimento mais prático, além disso, possibilita que os dados coletados sejam melhor categorizados e visualizados. Divulgamos o questionário pela rede social WhatsApp. Os convites foram realizados tanto individualmente quanto nos grupos. A divulgação do questionário ocorreu entre os dias 03/06/2020 e 30/06/2020.

Após a obtenção dos dados, os resultados foram analisados a partir da Análise de Conteúdo com base em Bardin (2011). Esse método visa categorização e pretende fornecer, por condensação, uma representação simplificada dos dados coletados. A análise por categoria se constituí a partir de um desmembramento textual em unidades, de acordo com reagrupamentos analógicos, ou seja, a partir da definição de critérios que irão classificar os elementos constitutivos de um conjunto por diferenciação e posteriormente o reagrupamento de termos, de acordo com o gênero. A análise tem as seguintes fases para a sua condução: organização da análise; codificação; categorização; tratamento dos resultados, inferência e a interpretação dos resultados.

Inicialmente foi realizada uma "leitura flutuante" das respostas que de acordo com Bardin (2011) significa obter o contato inicial com o material, criando familiaridade, com objetivo de captar conteúdos genericamente, obtendo as primeiras impressões sobre o material, analisando as informações e orientações presentes nele.

As categorias se configuram conforme as semelhanças entre os elementos, podendo a mensagem ser submetida a uma ou várias dimensões de análise. Tal categorização comporta duas etapas que incialmente isola os elementos dando lugar ao inventário, e posteriormente reparte os elementos, impondo certa organização às mensagens na etapa da classificação (Bardin, 2011). Sendo assim, os recortes das mensagens foram realizados a partir da recorrência das respostas e assim a categorização em interlocução com a perspectiva teórica foram, fidedignamente, alcançadas.

Segundo Bardin (2011) os conteúdos são distribuídos de acordo com as categorias, as unidades de contexto e de registro. Essas divisões analíticas são criadas pelos pesquisadores que visam organizar e sintetizar os dados, de forma que os textos dialoguem com o tema central da análise. Essas categorias constituem os pilares, como palavras-chaves, que reúnem e

\footnotetext{
${ }^{3}$ Futura dissertação de mestrado do programa de Pós-graduação em Educação Física da Universidade Federal do Rio de Janeiro (PPGEF/UFRJ). Aprovada pelo Comitê de Ética em Pesquisa do Colégio Pedro II, sob o CAAE 29847820.3.3001.9047 e Comitê de Ética em Pesquisa do Hospital Universitário Clementino Fraga Filho/HUCFF/UFRJ, sob o CAAE 29847820.3.0000.5257.
} 
sintetizam as unidades de contextos, gerando subcategorias que permitem compreender os sentidos da unidade de registro, resultando nos menores segmentos do conteúdo analisado, sendo assim, gerando o resultado do processo de categorização.

A unidade de registro objetiva fazer a categorização e contagem frequencial, já a unidade de contexto é feita nos documentos para que possamos compreender as unidades de registro, que visa individualizar a unidade de compreensão, codificando as unidades de registro, ao realizar o tratamento dos dados obtidos ocorre a condensação para dar ênfase as informações fornecidas pela análise e finalmente ocorre a interpretação dos dados (Bardin, 2011).

\section{Resultados e Discussão}

As respostas a esse questionário possibilitaram reflexões sobre a percepção docente frente o currículo cultural e a escrita curricular da Educação Física presente no Projeto Político Pedagógico do Colégio Pedro II, possibilitando reflexões sobre as diversas interpretações dos professores, diante dos princípios que orientam as suas seleções de temas de ensino.

A intenção era que o maior número de docentes respondessem o questionário, nos aproximando do total de 53 , que compõe o quadro efetivo do Departamento de Educação Física do Colégio Pedro II, no entanto, conseguimos 33 respondentes. A discussão sobre os dados obtidos serão discutidos nas próximas sessões.

\section{Conhecimento docente sobre o PPPI 2017/2020}

A primeira questão visava identificar se o docente possuía ou não conhecimento sobre o novo PPPI, essa questão foi elaborada com o objetivo de quantificar a média de professores que afirmariam ter lido o documento e para melhor visualização dos resultados, há o Gráfico 1, disposto a seguir:

Gráfico 1. Quantitativo docente que afirmam ter conhecimento sobre o PPPI.

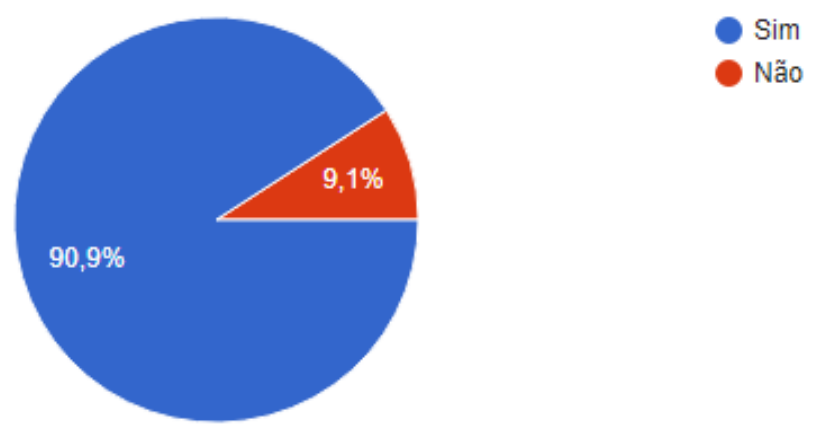

Fonte: Autores.

O Gráfico 1 demonstra que dos 33 respondentes, apenas 3 informaram não possuir conhecimento sobre o novo PPPI e uma pessoa não respondeu essa pergunta, o que demonstra que a maioria afirma conhecer o documento. $\mathrm{O}$ resultado apresentado talvez não se assemelhe com o que, ocasionalmente, ocorre com outras instituições de ensino país a fora, que muitas vezes distanciam o docente da construção curricular, consequentemente o afastando de seu conhecimento e implementação.

\section{Modificações curriculares observadas}

É importante ressaltar, que anterior a escrita do PPPI (2017-2020) havia o PPPI criado em 2002, ambos com uma parte destinada a escrita curricular da área da Educação Física, o primeiro, que possuía uma escrita incorporada a partir dos 
PCN's com viés crítico da Educação Física, reconhecendo a necessidade de evoluir de uma cultura do físico para uma cultura corporal, referenciando literatura clássica da área como o livro Metodologia do ensino da Educação Física (1993). Bem como mencionam Salgado et al., (2016, p. 6):

Editado pelo Instituto Nacional de Estudos e Pesquisas Educacionais, órgão do MEC, em 2002, o PPP do CPII pretendia adequar o currículo às novas determinações da política educacional do Brasil: LDB 9394/96 e aos PCN's, mudando o formato dos antigos guias curriculares e recontextualizando o conteúdo de ensino.

Nesse ínterim, entre a criação do primeiro e segundo PPPI, em 2011 foi criada uma proposta pedagógica voltada para o ensino da Educação Física nessa instituição, que propôs uma abordagem desenvolvimentista em sua escrita, especificando fases do desenvolvimento motor em prol de uma proficiência motora com ênfase no movimento como orientação das intervenções pedagógicas (Colégio Pedro II, 2011).

Com o intuito de identificar, na percepção dos professores, as modificações entre a proposta pedagógica anterior e o atual PPPI, foi solicitado a escrita de impressões sobre as modificações percebidas entre o atual PPPI (2017-2020) em comparação com a proposta pedagógica criada em 2011.

Os resultados demonstraram que a maior e quase totalidade das modificações identificadas pelos docentes caminham para o entendimento do abandono de uma perspectiva desenvolvimentista para aceitação de um currículo culturalmente orientado, como destacado em algumas respostas:

[...] O Novo currículo propõe uma educação física cultural, ancorada no multiculturalismo crítico. Já o anterior, trazia a proposta de uma educação física de cunho desenvolvimentista. (Professor 7)

[...] Em 2011 a proposta pedagógica da Educação Física no Colégio possuía como base teórica e princípio pedagógico o desenvolvimentismo; o atual (2017-2020) tem como base a teoria pós-moderna dos estudos culturais, mais especificamente o multiculturalismo. (Professor 9)

Saímos de um currículo mais tradicional para um currículo que abraçou mais as variadas formas da cultura corporal, que antes eram desconsideradas ou ignoradas pelo documento anterior. Esse novo currículo também proporcionou uma maior escuta do alunos do Colégio, algo que não era realizado antes desse período. (Professor 26)

Sim, existem grandes diferenças. A maior delas foi a mudança em relação a perspectiva de Educação Física, na primeira, a base curricular está fundamentada essencialmente na perspectiva desenvolvimentista, com alguns traços da crítica e do multiculturalismo assimilacionista, já a proposta atual, está ancorada em uma perspectiva pós-crítica ou cultural ou multicultural crítica de Educação Física. (Professor 30)

Esses dados são importantes por demonstrarem uma mudança de princípios que orientam as ações pedagógicas, consequentemente influenciando na intervenção docente, demonstrando que as novas perspectivas da disciplina tendem a ter mais afinidade com os princípios do currículo cultural.

Os princípios do currículo cultural notorizam o abandono de uma perspectiva que enfatiza a proficiência motora e o movimento, isso pois, uma peculiaridade da Educação Física cultural se refere a despreocupação com performance motora, o professor estimula o estudante a conhecer e vivenciar as manifestações da cultura corporal para, se necessário, reelaboralas e assim facilitar o entendimento da plasticidade da cultura e as transformações sofridas por todas as práticas corporais (Neira, 2018a). Sendo assim,

Ingenuidade é acreditar que a prática de atividade, por si só, resultará na melhoria da qualidade de vida do povo. Organizar atividades que estimulem os alunos a pensar criticamente implica fornecer elementos para lutar por melhores condições de vida, além de contesta discursos falaciosos (Francoso \& Neira, 2014, p. 533). 
Essa visão reducionista, que põem a Educação Física como espaço de centralidade promotora da saúde, por meio do exercício físico, por vezes, ignora os aspectos políticos sociais que contribuem para uma sociedade igualitária, saudável e com mais qualidade de vida, pois outros fatores, que não o simples movimentar-se, interferem na vida ativa, ou não, da população.

Centrados no conceito amplo de saúde, Ferreira (2001) nos relata a situação cotidiana de um indivíduo, que representa a realidade de boa parte da população, que reside em uma favela, acorda cedo, utiliza transporte público por horas para chegar ao trabalho, chega em casa tarde e ainda cuida dos afazeres domésticos. E nos faz refletir com a seguinte indagação: Como esse indivíduo se conscientizará da importância do exercício físico?

Ferreira (2001) ainda nos alerta sobre a importância de facilitarmos a compreensão do estudante frente a prática do exercício físico para além dos determinantes fisiológicos, biomecânicos, mas também sociopolíticos-econômicos e culturais dessa prática para um estilo de vida efetivamente mais ativo e sociedade mais justa.

Ao enfatizar um currículo centrado na aprendizagem esportiva, motora, pautada na noção restrita de saúde, qualquer diferença analisada se justifica por características natas, que de acordo com Macêdo et al. (2018), essas ações acabam também contribuindo para manutenção do status quo, pois a Educação Física, fincada nestes objetivos, focado no cuidado com o corpo por um viés unicamente biológico tende a reforçar conceitos e ideais dominantes da sociedade.

Esse contexto favorece a classificação de aptos, inaptos, hábeis, inábeis, com ênfase no desenvolvimento motor e nos padrões de movimento, corroborando para o ocultamento da diversidade cultural presente na escola. De acordo com Daolio (2010) ignorar a história marcada nos corpos dos estudantes não é uma conduta prudente, sendo assim, a diversidade deve ser considerada em aula.

Nesse sentido é importante lidar com as diferenças mitigando as desigualdades, evitando categorização de inferiores, superiores ou aptos e inaptos, e sim atingindo todos os estudantes sem distinção, reconhecendo o espaço escolar sociocultural que permite contato entre atores com diferentes interesses e visões de mundo (Daolio, 2010).

\section{Conhecimento docente sobre a Educação Física Cultural}

Considerando o referencial teórico que embasa o currículo de Educação Física, que constitui parte do PPPI dessa instituição, nos esforçamos em analisar se os docentes possuíam conhecimento sobre o currículo cultural. Na questão utilizamos nomenclaturas que podem ser associadas ao currículo cultural, tais como: Currículo Intercultural ou Multicultural Crítico. Os resultados podem ser melhor visualizados no Gráfico 2, abaixo:

Gráfico 2. Professores/as conhecedores da Educação Física cultural.

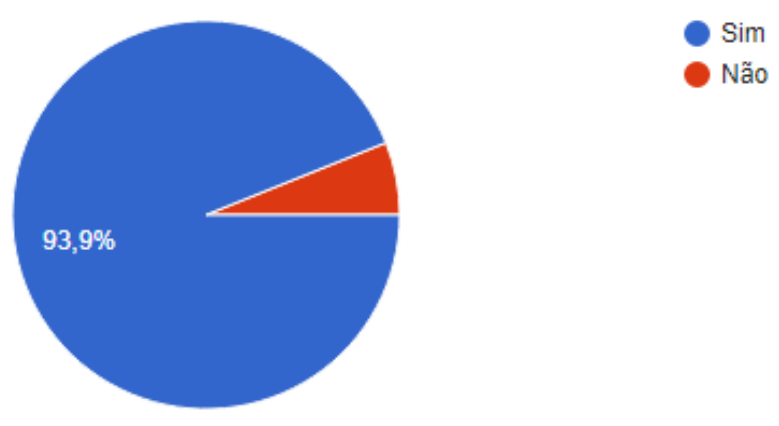

Fonte: Autores. 
O levantamento estatístico buscou refletir sobre quantitativo médio de professores que conhecem o currículo cultural. Observa-se nessa análise que do total de 33 respondentes, apenas 2 afirmaram desconhecer o currículo cultural, esse dado corrobora com nossas expectativas ao demonstrar que é quase totalitário o número de docentes que conhecem o currículo que embasa o PPPI, reafirmando a importância da criação desse documento contar com a participação docente ativa. Mas, é curioso analisar que os mesmos docentes que disseram não conhecer o currículo cultural, informaram na questão anterior que conhecem o PPPI. Além disso, os dados revelam que alguns respondentes desconhecem a Educação Física cultural, o que não era esperado, considerando a conjuntura de elaboração do PPPI e os aspectos nele abordados.

Nesse sentido, é importante ressaltar que essa forma de configuração curricular que se conveniou denominar Educação Física cultural, currículo cultural, culturalmente orientado ou currículo pós-crítico é recente e fortemente influenciada pelos estudos culturais e multiculturalismo critico que vem se difundindo na Educação Básica. Dentre outros princípios, valoriza e reconhece a diferença por meio da validação da cultura corporal dos múltiplos grupos que coabitam a sociedade, legitimando os saberes discentes e confrontando com outras representações sociais (Neira, 2018b).

\section{As práticas pedagógicas influenciadas pelo currículo cultural}

Conhecer o currículo não significa, necessariamente, que o professor vocalize alguma simpatia pela Educação Física cultural. Sendo assim, uma das questões visava identificar quais professores reconhecem sua atuação como sendo influenciada por tal currículo. O Gráfico 3 a seguir ilustra os resultados dessa questão.

Gráfico 3. Professores/as que colocam o currículo cultural em ação.

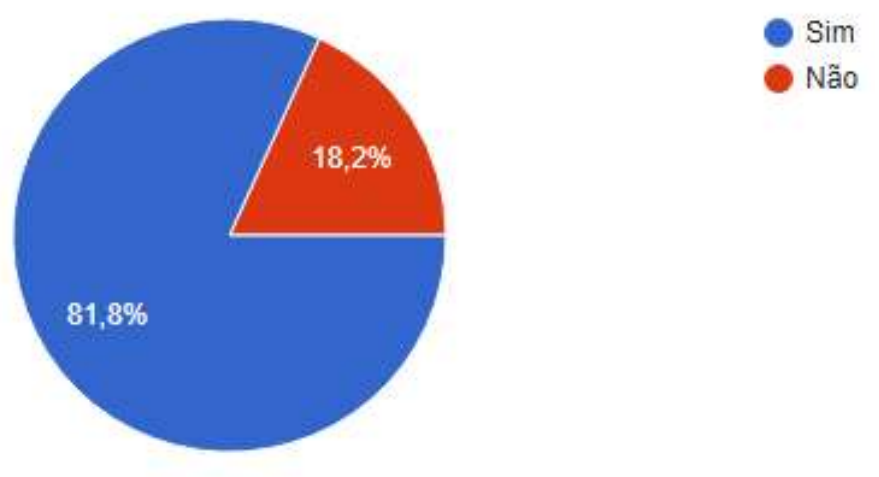

Fonte: Autores.

Diferentes teorias podem orientar a atuação docente, o esperado é que aquela perspectiva que embasa a escrita curricular do PPPI, ou seja, o currículo cultural, fosse a que mais influenciasse a totalidade das práticas pedagógicas dessa instituição, mas os resultados demonstram que 6 dos professores respondentes não possuem suas ações pedagógicas influenciadas pelo currículo cultural. Não se pode desconsiderar o contexto de formação inicial ou continuada a que muitos professores foram submetidos e que outras vertentes da área podem ser base influenciadora da atuação desses professores que responderam não colocar o currículo cultural em ação.

Buscamos, nesse sentido, problematizar e levantar possíveis motivações que levam docentes a não terem suas ações pedagógicas influenciadas pelo currículo cultural. Possivelmente, essa decisão pode estar relacionada com a formação docente pautada em um histórico esportivizante e desenvolvimentista (Darido \& Rangel, 2005). Além disso, o fato da própria disciplina sofrer pressão para que tenha seus temas de ensino pensados com foco em conhecimentos hegemônicos. 
O processo de legitimação da área está atrelado a cultura do esporte e promoção da saúde, que explica a falta de superação da visão biofisiológica (Bracht, 2019).

O que corrobora com o que foi descrito por Silva (2008) e Gomes (2011), ao investigarem a formação inicial e continuada docente e destacarem que embora tenham identificado discursos que preconizavam a diversidade cultural, perceberam maior ênfase a vertente multicultural folclórica ${ }^{4}$ do que ao multiculturalismo crítico. $\mathrm{O}$ que já havia sido investigado por Apple (1999) quando afirmou que os temas de ensino oriundos da cultura acadêmica contribuem para a manutenção da hegemonia dos grupos empoderados. A formação acadêmica pode interferir na atuação docente, provavelmente os conteúdos aprendidos no período de formação, serão aqueles que irão compor o repertório de temas selecionados na atuação pedagógica. Em contrapartida, educadores que artistam $^{5}$ ou ao tentam artistar a proposta do currículo cultural fazem-no sob a influência de certos princípios, o que os leva a promover especificas situações didáticas, organizando-as e conduzindo-as de forma peculiar (Neira \& Nunes, 2020).

Não se pode desconsiderar também a autonomia docente frente a seleção dos temas de ensino. Ou seja, é opcional o professor guiar suas estratégias de ensino frente o currículo cultural, o que não significa que sua atuação docente seja ou não significativa, como não sabemos quais teorias direcionam a ação pedagógica dos que disseram não serem influenciados pelo currículo cultural, não podemos fazer nenhuma análise sobre isso.

É importante destacar, no entanto, que os docentes que afirmaram artistar o currículo cultural, foram subsequentemente solicitados a responder discursivamente o que eles consideram ser uma intervenção pedagógica pautada no multiculturalismo crítico, aos que responderam afirmativamente a pergunta anterior, nos interessará o que descreveram na referida questão.

\section{Interpretações sobre práticas pedagógicas culturalmente orientadas}

Outro levantamento que buscamos realizar foi o entendimento dos professores sobre práticas culturalmente orientadas. Cabe ressaltar no entanto, que o objetivo dessa questão não é o de rotular o que é o currículo cultural, apenas analisar se os professores orientam sua ação pedagógica aproximada dos princípios que, momentaneamente, compõe esse currículo, isso pois, de acordo com Neira e Nunes (2020) não há como roteirizar, realizar um manual, receita ou guia do currículo cultural, na verdade, fazer isso seria se contrapor ao que preconizam as teorias pós-críticas.

Durante a leitura e análise das respostas, que trouxeram diversas interpretações frente as aproximações da perspectiva cultural da Educação Física, definimos as categorias, de acordo com a similaridade temática apresentada. Assim, foram criadas quatro categorias: Formação cidadã) Valorização da diversidade e diferença (diversidade social/ diversidade de temas); Valorizar cultura minoritárial problematização das relações de poder; Interesse do estudante e valorização da própria cultura, e serão desenvolvidas na próxima sessão.

$\mathrm{Na}$ categoria Formação cidadã elucidamos falas aproximadas do que preconiza o currículo cultural, quando, por exemplo, o professor 7 escreve que uma prática pedagógica culturalmente orientada implica na "formação de sujeitos solidários e éticos" essa resposta está em conformidade com o que afirma Duarte e Neira (2020) ao fazer um levantamento

\footnotetext{
${ }^{4}$ Denomina-se multiculturalismo liberal ou folclórico a redução das estratégias de trabalho a aspectos exóticos, folclóricos e pontuais, como quando oferece-se uma abordagem superficial e turística às festas juninas, à dança de quadrilha e ao dia do Índio, por exemplo. Utiliza-se uma abordagem ética e democrática, porém, são incapazes de reconhecer que o poder se distribui de forma desigual na sociedade, o que consequentemente acaba favorecendo a manutenção do status quo (Canen, 2012; Neira \& Nunes, 2009; Neira, 2016a).

${ }^{5}$ O termo "artistar" foi tratado por Corazza (2006) com uma ideia que foge da normatização. Esse termo está relacionado à entrega ao caos para criações em desenvolvimento, inacabada, incompreensível, contingente, múltipla e finita de marcas livres, irracionais, involuntárias, acidentais. Implica no trabalho do professor atuando nas fronteiriças, na penumbra da cultura, no compartilhamento da linguagem. É uma forma de escrever, nem melhor nem pior do que as outras formas, nem mais progressista, evoluída, lógica, natural ou científica, mas, capaz de comover.
} 
sobre os princípios do currículo cultural e descrevem que há "[...] engajamento na afirmação das diferenças e na tentativa de formar sujeitos solidários.” (Duarte \& Neira, 2020, p.296).

Já a categoria Valorização da diversidade e diferença (diversidade social/ diversidade de temas) reuniu falas docentes que elucidaram a importância de valorizar a diversidade tanto social, quanto a possibilidade de diversificar os temas de ensino abordados em aula, enfocando na ampliação de possibilidades a serem tematizadas, e falas que ressaltaram a importância de validar as diferenças. Como destacado nas respostas a seguir:

[...] reconhecimento e valorização das diversas vozes que habitam a espaço social [...] (Professor 5)

Reconhecimento e tensionamento das diferenças nos planejamentos, estratégias e ações nas aulas de Educação Física. (Professor 10)

Muito resumidamente acredito que é uma intervenção que considera as diferenças uma riqueza [...] (professor 14)

Que valoriza a diversidade de temas, a inclusão de todas as formas de diferenças [...] (Professor 23)

O currículo cultural visa formar sujeitos solidários, comprometidos com o reconhecimento da importância de toda e qualquer pessoa, independente de sua condição social de classe, raça, étnica, gênero ou religião, ou seja, favorável as diferenças (Neira, 2020). É nessa inter-relação entre representações e frente a diversidade cultural que a chamada política da diferença ganha destaque e é justamente nas relações de poder existente entre os grupos, que são estabelecidas identidades válidas e representativas. A resistência à hegemonia das identidades é luta constante dos grupos desprovidos de poder, que buscam o direito a representatividade (Neira, 2010).

A valorização e respeito às diferenças e o questionamentos a favor de quem não é reconhecido é fundamental por favorecer o processo de identificação e reconhecimento indenitário, possivelmente evitando discursos e práticas que veiculam injustiças. "[...] E a ausência de uma reflexão sobre as formas pelas quais as diferenças são produzidas dificulta a formação de identidades democráticas." (Neira, 2018b, p.15).

Um ponto de partida em comum estabelecido por aqueles que afirmam ter uma prática pedagógica culturalmente orientada é a afirmação das diferenças (Duarte \& Neira, 2020). Além disso, promovem uma reflexão acerca da construção das diferenças, sem se limitar ao seu respeito e tolerância, mas além, valorizando-as e promovendo permanente problematização e questionamento, principalmente do modo como se produzem e alastram os discursos pejorativos, facilitando o entendimento das relações assimétricas (Neira, 2018a).

Nesse sentido, reconhecendo a diferença como a própria riqueza da sociedade, identificamos o currículo cultural como um caminho possível para encarar a diferença assim e para tantos outros fins, como o de caminhar no sentido de culminar em processos sociais e curriculares mais justos, em prol da inclusão e do reconhecimento indenitário.

No que tange a consideração da diversidade de temas de ensino em aula, a literatura nos mostra que:

As danças juvenis, as brincadeiras urbanas atuais e do passado, as modalidades esportivas radicais e internacionais, as práticas corporais alternativas e as lutas brasileiras ou estrangeiras, mesmo que de menor visibilidade midiática, são tão legitimas quanto aquelas mais conhecidas, e por isso, devem ter resguardado seu lugar dentre as temáticas abordadas pelo currículo escolar (Neira, 2011, p.148).

Além disso, Neira (2018a) reforça que as práticas consideradas hegemônicas devem receber atenção equiparada a tantas outras práticas como o funk, o skate, a capoeira, o carrinho de rolimã, o hip hop, o parkour e o baralho, por exemplo. Quanto maior o leque de possibilidades apresentadas, maior a possibilidade de uma possível identificação por parte dos 
estudantes (Fonseca \& Ramos, 2017). Afinal, para uma criança que conhece apenas o futebol e basquete, por exemplo, será difícil se identificar por capoeira.

Entretanto, segundo Françoso e Neira (2014) é importante o aproveitamento do tempo de aula para reflexão crítica da ocorrência das manifestações vivenciadas na sociedade. Abordando esses conhecimentos de forma mais cuidadosa, evitam, assim, ampliar os temas de ensino nas aulas considerando apenas o quantitativo de práticas corporais. Esse discurso é, por vezes, defendido como justificativa de expansão do repertório motor dos/as estudantes em prol de uma competência profissional (docente), tratando esportes, danças, lutas e ginásticas, por vezes, de forma superficial e descontextualizada.

Valorizar cultura minoritária/ problematização das relações de poder foi a categoria que agrupou respostas que ressaltaram a importância dada pelo currículo cultural a valorização da cultura silenciada e que reconhece o espaço de aula como local possível de problematização das relações de poder, bem como ressaltado nas respostas em destaque:

Aquela que dá voz aos grupos minoritários/excluídos e problematiza essas questões em suas aulas. (Professor 6)

[...] Discussão das relações de poder existentes e com uma preocupação com uma justiça social e curricular. (Professor 8)

[...] Uma educação atenta a preconceitos e as construções históricas de discriminação de grupos minoritários e busca intervir de maneira justa em que todas as diferenças tenham voz no currículo. (Professor 14)

[...] Privilegia conteúdos antes relegados como subalternos. (Professor 23)

Uma intervenção que promova um diálogo, valorize os diversos saberes e culturas dos alunos, que tenha compromisso com a justiça social, que exalte a pluralidade cultural... (Professor 24)

Esse discurso produzido corrobora com o que tem sido evidenciado na literatura sobre o currículo cultural, como descreveram Duarte e Neira, (2020) ao explicarem que ações pedagógica culturalmente orientadas tendem a reconhecer e valorizar os conhecimentos produzidos por grupos considerados minoritários, permitindo que os estudantes acessem e compreendam como determinados saberes são silenciados e negligenciados enquanto outros se tornaram hegemônicos. Sendo assim, estudar as culturas periféricas e se posicionar a favor dos mais fracos é uma característica distintiva do currículo cultural (Neira, 2018a), além disso, é importante refletir que:

[...] Não pode haver nada mais nocivo do ponto de vista didático que a concordância silenciosa ou o pensamento homogêneo, isto é, ao apresentar aos estudantes um só ponto de vista sobre as coisas do mundo, corre-se o risco de padronizar as referências de análise, deixando de fora muitas outras possibilidades (Neira, 2020).

$\mathrm{O}$ espaço de aula pode tanto contribuir para conformação e mesmice que mantem a ideologia vigente, favorecendo grupos que historicamente desfrutam de certa vantagem social, como também contribuir para um espaço rico de oposição a cultura dominante (Neira \& Nunes, 2006). Nesse sentido, por meio da ressignificação, historicizando, politizando, culturalizando e inventando novas e ousadas manifestações corporais o currículo cultural propõe prática contra hegemônica, ou seja, que não silenciem ou marginalize os grupos subalternizados (Neira, 2011). Ao contrário visa o reconhecimento da produção discursiva desses grupos minoritários, seja essa produção verbal ou não (Santos \& Neira, 2019)

Na categoria Interesse do estudante e valorização da própria cultura elencamos as falas docentes que destacaram a relevância da validação das vozes discentes. Como ressaltado nas falas destacadas: 
Essa intervenção deve dialogar com a cultura corporal de movimento ${ }^{6}$ que aquele grupo de estudantes possua e/ou a localidade que a escola esteja inserida. (Professor 17)

Uma intervenção que se baseia no mapeamento, para tematizar elementos da cultura corporal que dialoguem com a realidade dos alunos e ao mesmo tempo aprofunde o repertório dos mesmos sobre essa prática corporal (Professor 18)

[...] Atores envolvidos no processo pedagógico passam a ter sua voz ouvida e considerada [...] (Professor 26)

O que vai ao encontro do que temos encontrado na literatura: Parece que a área da Educação Física tem tentando desenvolver estratégias que aproximem as percepções dos educandos da ação pedagógica (Prodócimo, Spolaor \& So, 2019). No entanto, cabe ressaltar que não significa necessariamente permanecer na cultura do estudante, mas considerar a importância dos saberes que estão sendo produzido, permitindo o entrecruzamento com o conhecimento de outras culturas (Fancoso \& Neira, 2014).

\section{Conclusão}

Diante das análises realizadas, pode-se destacar que há entendimento sobre o que vem a ser, ainda que momentaneamente, o currículo cultural por parte dos professores de Educação Física do Colégio Pedro II. Diante das respostas discursivas, observamos que os professores descrevem princípios que a literatura aponta como sendo do currículo cultural, como quando validam os saberes discentes, as diferenças, a própria cultura, as culturas silenciadas, reconhecem a importância de problematizar as relações de poder e valorizam a diversidade.

Quase todos os professores disseram conhecer o PPPI e o Currículo cultural. Além disso, a grande maioria afirmou colocar ou tentar colocar o currículo cultural em ação. As modificações observada pelo corpo docente entre a proposta pedagógica de 2011 e o novo PPPI 2017/2020 apontam para um abandono de uma perspectiva desenvolvimentista e adoção de práticas pedagógicas culturalmente orientada, o que evidencia uma mudança de perspectiva curricular nessa instituição.

Sendo assim, essa nova concepção de Educação Física vem efetivamente ganhando espaço nos princípios norteadores discursados por esses docentes que atuam em uma instituição federal do Rio de Janeiro. No entanto, a análise do questionário deixa algumas lacunas, embora respondam positivamente sobre ter uma prática culturalmente orientada, apenas um estudo de campo com observação de aulas, com narrativas de experiências poderemos confrontar os dados com a literatura e elucidar outros conhecimentos.

Mas os dados aqui expostos nos ajudam a refletir sobre como vem se construindo o currículo da disciplina na instituição e como tem sido essa aceitação e entendimento docente. Portanto, considerando os limites teórico práticos, as respostas obtidas geram outros questionamentos, que anunciam a importância de estudos que investiguem o cotidianos das aulas. Nesse sentido, concordamos com Neira (2018d) ao mencionar a importância de estudos que visam compartilhar caminhos possíveis de práticas pedagógicas culturalmente orientadas, pois para o autor, é a partir das investigações realizadas com o currículo cultural é que poderemos teorizar a seu respeito.

Sendo assim, possibilidades de futuras pesquisas seriam possíveis, por exemplo, a partir do confronto de teorizações curriculares sob a perspectiva multicultural crítica e a realidade vivida em aula, no cotidiano escolar, com observações de aulas, registro em caderno de campo, ou estudo etnográfico sob a mesma ótica no Colégio Pedro II, ou também pesquisas de mesma natureza em outras instituições escolares com diferentes realidades e contextos.

\footnotetext{
${ }^{6}$ Vale ressaltar que a partir de novos significados atribuídos às brincadeiras, danças, lutas, ginástica e esporte, passíveis de inúmeras interpretações a depender do contexto e dos sujeitos envolvidos, a perspectiva pós-critica adotou o termo "cultura corporal" abdicando da expressão "cultura corporal de movimento" para além da linguagem corporal, a fim de se pensar em discursos que envolvam as práticas corporais e seus representantes (Neira, 2018a, 2018b).
} 


\section{Referências}

Apple, M. W. (1999). Poder, significado e identidade: ensaio de estudos educacionais críticos. Porto Editora.

Bracht, V. (2019). A educação física escolar no Brasil: o que ela vem sendo e o que pode ser. UNIJUI.

Brasil. (2011). Colégio Pedro II. A Educação Física como componente curricular da educação básica no Colégio Pedro II. MEC/ Rio de Janeiro: Colégio Pedro II.

Canen, A. (2012). Currículo e multiculturalismo: reflexões a partir de pesquisas realizadas. In: Santos, L.L. de C.P. \& Favacho, A.M.P. (Org.). Políticas $e$ práticas curriculares: desafios contemporâneos. Curitiba, SC: Editora CRV, 237-49.

Colégio Pedro II. (2016a). Componentes curriculares - formatação para PPPI.

Colégio Pedro II. (2018). Departamento de Educação Física. In: COLÉGIO PEDRO II. Projeto Político Pedagógico Institucional Colégio Pedro II. p.234-260. Disponível em: http://www.cp2.g12.br/images/comunicacao/2018/JUL/PPPI\%20NOVO.pdf Acesso em: 29/06/2020.

Corazza, S. M. (2006) Artistagens: filosofia da diferença e educação. Belo Horizonte: Autêntica.

Darido, S. C. \& Rangel, I. C. A. (Coords.). (2005) Educação Física na escola: implicações para a prática pedagógica. Rio de Janeiro: Guanabara Koogan.

Daolio, J. (2010) (coord.). Educação Física escolar: olhares a partir da cultura. GEPEFIC-Grupo de Estudo e Pesquisa Educação Física e Cultura. Campinas, SP: Autores associados, 2010.

Duarte, L. C. \& Neira, M. G. (2020). Currículo cultural da Educação Física: a produção de uma pedagogia engajada. Humanidades \& Inovação, 7, 283-300.

Ferraz, O. L. \& Correia, W. R. (2012) Teorias curriculares, perspectivas teóricas em Educação Física Escolar e implicações para a formação docente. Revista Brasileira de Ciências do Esporte, 26(3), 531-40.

Ferreira, M. S. (2001). Aptidão Física e saúde na Educação Física escolar: ampliando o enfoque. Revista Brasileira de Ciências do Esporte, 22(2), 41-54.

Fonseca, M. P. S. \& Ramos, M. M. R. (2017). Inclusão em movimento: discutindo a diversidade nas aulas de educação física escolar. In: PONTES JUNIOR, José Airton de Freitas (Org.). Conhecimentos do professor de educação física escolar [livro eletrônico]. EdUECE, 184-208.

Francoso, S. \& Neira, M. G. (2014). Contribuições do legado freireano para o currículo da Educação Física. Revista Brasileira de Ciências do Esporte. 36(2), $531-46$.

Gomes, I. M., Almeida, F. Q. \& Bracht, V. (2010). O local da diferença: desafios à educação física escolar. Pensar a Prática, Goiânia, 13 (1), 1-15.

Lopes, A. C. \& Macedo, E. (2011). Teorias do Currículo. Cortez.

Macêdo, L.D. S., Ramos, T. M., Purificação, T. A. \& Neira, M. G. (2018) Análise de atos de currículo na educação física em escolas da rede municipal de Simão Dias - SE e Paripiranga - BA, Conexões, 16(3), 281-98.

Mclaren, P. (2003). Life in schools: na introduction to critical pedagogy in the fundations of education (4th ed), Allyn and Bacon, Albany, NY.

Miskolci, R. \& Leite Junior, J. (Org.). (2014). Diferenças na Educação: outros aprendizados. EdUFSCar, 1, 253.

Moreira, A. F. B. \& Candau, V. M. (2003). Educação escolar e cultura(s): construindo caminhos. Rev. Bras. Educ., 156-68.

Neira, M. G. (2020). A abordagem das diferenças no currículo cultural da Educação Física. Humanidades \& Inovação, 7, $39-56$.

Neira, M. G. (2010). Análises das representações dos professores sobre o currículo cultural da Educação Física. Interface (Botucatu), 14(35), 783-95.

Neira, M. G. (2018d). Currículo cultural da Educação Física: pressupostos, princípios e orientações didáticas. Revista e-Curriculum, São Paulo, 16(1), 4-28.

Neira, M. G. (2018a). Educação Física cultural: inspiração e prática pedagógica. Paco. 1, 166.

Neira, M. G. (2011). Educação Física. Col. A reflexão e a prática no ensino - Educação Física. Blucher.

Neira, M. G. (2018b). Incoerências e inconsistências da BNCC de Educação Física. Revista Brasileira de Ciências do Esporte, Porto Alegre, $40(3), 215-23$.

Neira, M. G. (2016a). Multiculturalismo crítico e suas contribuições para o currículo da educação física. Temas em Educação Física Escolar, 1(1), 3-29.

Neira, M. G. (2020). Os conteúdos no currículo cultural da Educação Física e a valorização das diferenças: análises da prática pedagógica. Revista eCurriculum, [S.1.], 18(2), 827-46, ISSN 1809-3876.

Neira, M. G. \& Nunes, M. L. F. (2020). As dimensões política, epistemológica e pedagógica do currículo cultural da Educação Física. In: Bossle, F., Athayde, P. \& Lara, L. Educação Física escolar. Natal: EDUFRN, 25-43.

Neira, M. G. \& Nunes, M. L. F. (2006). Pedagogia da cultura corporal: críticas e alternativas. Phorte.

Neira, M. G. \& Nunes, M. L. F. (2009). Educação Física Currículo e Cultura. Phorte.

Neira, M. G. \& Santos, I. L. (2019). A reterritorialização do pensamento freireano no currículo cultural da Educação Física. In: Souza, C. A., Nogueira, V. A. \& Maldonado, D.T. (Org.) Educação Física Escolar e Paulo Freire: ações e reflexões em tempos de chumbo. 38, CRV. 
Research, Society and Development, v. 10, n. 9, e47010918288, 2021

(CC BY 4.0) | ISSN 2525-3409 | DOI: http://dx.doi.org/10.33448/rsd-v10i9.18288

Nelson, C., Treichler, P. A. \& Grossberg, L. (2013). Estudos Culturais: uma introdução. In: Silva, T.T. (Org.). Alienígenas na sala de aula: uma introdução aos estudos culturais em educação. (11a ed.). Vozes, 2013. 7-38.

Prodócimo, E., Spolaor, G. C. \& So, M. R. (2019). O pensamento de Paulo Freire e ações pedagógicas no cotidiano da Educação Física Escolar no Brasil. In: Souza, C. A., Nogueira, V. A. \& Maldonado, D. T. (Org.) Educação Física Escolar e Paulo Freire: ações e reflexões em tempos de chumbo. 38, Curitiba, SP; CRV.

Salgado, S. S. et al. (2016). A reforma currícular do Colégio Pedro II e o currículo da disciplina Educação Física. J. Phys. Educ., 27, e 2, 747

Salles, F. L. (2019). A tessitura curricular em uma comunidade de aprendizagem docente multicultural: o caso da disciplina Educação Física. Rio de Janeiro. 256 f. Tese (Doutorado em Educação) - Faculdade de Educação, Universidade Federal do Rio de Janeiro, Rio de Janeiro, 2019.

Santos Júnior, F. N. \& Neira, M. G. (2020) Olhares sobre a proposta de reorganização do currículo do ensino médio na rede estadual paulista. Revista Internacional de Formação de Professores.

Silva, T. T. (2015). Documentos de Identidade: Uma Introdução às Teorias de Currículo. (3a ed.), Editora Autêntica.

Triviños, A. N. S. (1987). Introdução à pesquisa em ciências sociais: a pesquisa qualitativa em educação. Atlas.

Venancio, L. \& Darido, S. C. (2012). A educação física escolar e o projeto político pedagógico: um processo de construção coletiva a partir da pesquisa-ação. Rev. bras. educ. fis. esporte, 26(1), 97-109.

Williams, J. (2013). Pós-estruturalismo. Tradução de Caio Ludvik. (2a ed.), Vozes. 